\title{
Prevalence and impact of burnout, secondary traumatic stress and compassion satisfaction on hand hygiene of healthcare workers in medical aid team during COVID-19 pandemic
}

\author{
Qian Zhou \\ Huazhong University of Science and Technology \\ Xiaoquan Lai \\ Huazhong University of Science and Technology \\ Chaoyang Wan \\ Peking Union Medical College Hospital \\ Xinping Zhang ( $\nabla$ xpzhang602@hust.edu.cn ) \\ Huazhong University of Science and Technology https://orcid.org/0000-0002-0688-2417 \\ Li Tan \\ Huazhong University of Science and Technology
}

\section{Research}

Keywords: burnout, secondary traumatic stress, compassion satisfaction, hand hygiene, medical aid, healthcare workers

Posted Date: May 19th, 2020

DOI: https://doi.org/10.21203/rs.3.rs-28820/v1

License: (c) (i) This work is licensed under a Creative Commons Attribution 4.0 International License. Read Full License 


\section{Abstract}

Background

Healthcare workers suffered mental burden, especially in the period of COVID-19. Professional quality of life quality is suitable to measure how healthcare workers feel in medical aid team. Current evidence of impact of professional quality of life on hand hygiene behavior or even IPC measures was limited, especially in emerging infectious disease period. This study aimed to assess the prevalence of burnout, secondary traumatic stress and compassion satisfaction and explore their impact on self-reported hand hygiene behavior among medical aid team in Wuhan, China, where strict management was conducted to prevent COVID-19 spread and guarantee healthcare workers' health.

\section{Results}

A cross-sectional study was conducted using online questionnaire covering professional quality of life and self-reported hand hygiene behavior based on COVID-19 guideline. A total of 1,734 healthcare workers were surveyed. The prevalence of burnout, secondary trauma and compassion satisfaction were low and average levels (69.61 and $30.39 \%)$, low and average levels (33.33 and 66.21\%), average and high levels (49.65 and 49.71\%), respectively. Burnout was negatively associated with overall hand hygiene (Coef. $=-0.088, p<0.001$ ), low hand hygiene (Coef. $=-0.109$, $p<0.001$ ), medium hand hygiene (Coef. $=-0.088, p<0.001)$ and high hand hygiene (Coef. $=-0.065, p<0.001)$.

Conclusions

Healthcare workers with higher compassion satisfaction reported higher hand hygiene compared to the lower. Healthcare workers in medical aid team experience lower level burnout, and higher level of compassion satisfaction during COVID-19 pandemic compared to the general period. The lower burnout and higher compassion satisfaction are associated with higher self-reported hand hygiene behavior. Burnout and compassion satisfaction in healthcare workers should be emphasize and need interventions targeting. The management of healthcare workers in Wuhan, China may be constructive for the future medical aid team.

\section{Introduction}

COVID-19 is an emerging infectious disease caused by SARS-CoV-2. With this virus spread globally, WHO declared the outbreak a Public Health Emergency of International Concern on 30th January, and a pandemic on 11th March. Up to the 8th May, 3.8 million people were diagnosed with COVID-19 across the world, which contained a large number of healthcare workers (HCWs). This pandemic of COVID-19 underlined how crucial it is to develop a comprehensive system to sustain health of HCWs at health facility[1, 2]. In COVID-19 outbreak period, a total of 42,322 HCWs coming from all over the country joined the medical aid team for Hubei province, to relieve the shortage of health human resource in China.

Hand hygiene behavior is crucial in COVID-19 pandemic, and the high compliance of hand hygiene is the cornerstone to protect HCWs and keep patients safe. The inappropriate adherence of hand hygiene may induce terrible cross-infection between HCWs and patients, causing unnecessary morbidity, mortality and healthcare cost[3]. Current studies have explored the impact of knowledge, attitude, awareness and socio-demographic characteristic on hand hygiene comprehensively, while the impact of psychological status is little known[4-7]. Although Colindres and Manomenidis found that burnout was the predictor of lower hand hygiene, the small sample size limited the generalization of the two studies[7, 8]. In summary, the evidence concerning the influence of psychological status on hand hygiene was limited. 
HCWs in medical aid team have a high risk of experiencing traumatic symptoms, including burnout, secondary traumatic stress, anxiety, etc.[9], because they suffer more bio-psycho-socio-behavioral risk factors than general HCWs, including adapting to a different culture, the disruption of family and social networks, isolated living environment and long working hours, etc.[10]. Professional quality of life (ProQOL) is defined as "the quality one feels in relation to their work as a helper", which is appropriate for individuals exposed to potentially traumatizing events, as a result of paid or volunteer work, like medical aid team[11]. ProQOL incorporated both positive and negative aspects, including burnout, secondary traumatic stress and compassion satisfaction. Current evidence in the prevalence of HCWs' psychological status is limited in medical aid team.

Researchers found that negative aspects of ProQoL in HCWs are associated with the poor quality of care, including poor quality and safety measures and unprofessional behavior, etc. [12,13]. The compassion satisfaction means that individuals feel happy with the work and want to continue, and the worse compassion satisfaction were reported to reduce the standards of care[11, 14]. Current evidence of impact of ProQoL on hand hygiene behavior or even infection prevention and control (IPC) measures was limited, especially in emerging infectious disease period. Gap remains in the impact of ProQOL on the hand hygiene behavior during COVID-19 pandemic. This study aimed to assess the prevalence of burnout, secondary traumatic stress and compassion satisfaction among HCWs in medical aid team and explore their impact on hand hygiene, to improve psychological statues and enhance hand hygiene behavior of HCWs in medical aid team.

\section{Materials And Methods Study settings}

A cross-sectional study was conducted at Tongji Hospital in Huazhong University of Science and Technology, Wuhan, China. A total of 828 beds were available to treat COVID-19 patients, and 1,462 patients were admitted, among whom 1,341 were cured, between $2^{\text {ed }}$ February and 30th March 2020. The HCWs were mainly composed of 17 medical aid teams from other hospitals across the whole country. Up to now, no HCWs from medical aid teams was infected with COVID-19.

\section{Management Of Medical Aid Team}

The hospital adapted a series of measures in the management of medical aid team to guarantee the requirement in COVID-19 prevention and control. In addition to the support from government, spontaneous civilian power also played a significant role in this management process. (Table 1) 
Table 1

The measure and detail in the management of medical aid team

\begin{tabular}{|ll|}
\hline Measure & Detail \\
\hline $\begin{array}{l}\text { Shift } \\
\text { management }\end{array}$ & $\begin{array}{l}\text { 1.Nurses shifted every four hours; doctors shifted every six hours. } \\
\text { 2.Days off were set based on the number of patients. } \\
\text { 3.One nurse cared for no more than two patients, based on the severity of patients. }\end{array}$ \\
$\begin{array}{l}\text { Protective } \\
\text { equipment }\end{array}$ & $\begin{array}{l}\text { A protective suit, a gown, a goggle or a face shield, three layers of gloves, an ordinary shoe } \\
\text { covers and a waterproof long shoe cover were provided every shift. Adult diapers were used in } \\
\text { work time. }\end{array}$ \\
$\begin{array}{l}\text { Education and } \\
\text { meeting }\end{array}$ & $\begin{array}{l}\text { 1.Educations were developed by leader group, and delivered to doctors and nurses by } \\
\text { department managers via video or text. }\end{array}$ \\
$\begin{array}{l}\text { 2.Meetings were held among the managers every week, discussing the flow formulation, } \\
\text { position arrangement, obligation confirmation and measure improvement, and delivered to } \\
\text { doctors and nurses by department managers via text. }\end{array}$ \\
$\begin{array}{l}\text { 3.HCWs must wear mask and keep one-meter distance with each other in the meetings. } \\
\text { measures }\end{array}$ & $\begin{array}{l}\text { Surveillance of daily health and risk exposure of HCWs were conducted. Nasopharyngeal swab } \\
\text { and blood sample were collected every month. The flow of treatment for HCWs was formulated, } \\
\text { if HCWs were suspected or diagnosed and etc. }\end{array}$ \\
\hline $\begin{array}{l}\text { Psychological } \\
\text { support }\end{array}$ & $\begin{array}{l}\text { Psychological supports were provided by psychological professors via telephone. The } \\
\text { telephone numbers were given to HCWs; they can contact if necessary. }\end{array}$ \\
$\begin{array}{l}\text { Financial } \\
\text { support }\end{array}$ & $\begin{array}{l}\text { The salary of medical aid team included one part from the original hospital and the other from } \\
\text { local subsidies of Wuhan from district service center, aid hospital and the Red Cross. }\end{array}$ \\
$\begin{array}{l}\text { Accommodation } \\
\text { and } \\
\text { transportation } \\
\text { measures }\end{array}$ & $\begin{array}{l}\text { The medical aid team resided in hotel, which also provided the meal. HCWs transported } \\
\text { between hotel and hospital via special shuttle bus. }\end{array}$ \\
\hline
\end{tabular}

\section{Data Collection}

A structured self-administered questionnaire was used to collect the data from 5th to 7th March 2020. HCWs in medical aid teams who were willing to take part in the study submitted the finished online questionnaires, which included the self-reported hand hygiene, ProQOL scale and socio-demographic characteristics. A total of 1734 HCWs were surveyed.

\section{Measurements}

\section{Dependent variables}

\section{Self-reported hand hygiene}

The outcome indicator was the self-reported hand hygiene, because the compliance of the other important measure, namely use of personal protective equipment (PPE), was approximately $100 \%$ due to the strict management of medical aid team, including sufficient supply of protective equipment and the obligatory requirement of government, etc., at the time of investigation. Hand hygiene behavior was measured by 18 moments of hand hygiene based on the IPC guideline issued by National Health Commission of China, along a five-point Likert scale that ranges from 1 (never) to 5 score (very often), reflecting the frequency of hand hygiene. The 18 moments consisted of the moments before 
touching a patient, before aseptic procedure, after body fluid exposure risk, after touching a patient, after touching patient surroundings, during work on a soiled body site to a clean body site on the same patient, before putting on PPE, before after and during removing PPE, before wearing glove, after removing glove, arriving at and leaving work place, before drinking, before and after toilet, before returning to the place of residence. We included the overall and three categories of hand hygiene as outcome. The hand hygiene behavior was divided into three categories as low, medium and high level of hand hygiene, behavior based on the score order of each moment, which was calculated by the average score of hand hygiene of each scope[15].

\section{Independent Variables}

\section{ProQOL}

The ProQOL Scale of Chinese version was adopted to assess burnout, secondary traumatic stress and compassion satisfaction using a five-point Likert scale that ranges from 1 (never) to 5 (very often)[16]. In this study, internal consistency ranged from acceptable to strong: burnout ( $\alpha=0.869$; good), secondary traumatic Stress ( $a=0.756$; acceptable) and compassion satisfaction ( $a=0.936$; strong). And construct validity was shown to be strong in previous study[17]. The 30-item ProQOL scale consists of three subscales: compassion satisfaction (10 items), burnout (10 items) and secondary traumatic stress (10 items). The items 1, 4, 15, 17 and 29 are reverse scored. Compassion satisfaction refers to positive feelings or sense of self-efficacy derived from helping others[18]. As compassion fatigue, burnout is related to frustration with work situation and colleague, whereas secondary traumatic stress is unique to the health care profession and patient care[19]. Each subscale score of 22 or less suggests low levels of compassion satisfaction, burnout and secondary traumatic stress; scores of 23-41 indicate average levels; and 42 and above suggest high levels[11].

\section{Socio-demographic Characteristics}

The socio-demographic characteristics variables were collected, including gender (male vs. female), career type (doctor vs. nurse), age, work year and work load. The work load was measured using self-reported five-point Likert scale (ranged from very low to very high).

\section{Statistical analysis}

Categorical variables were described using percentage and frequency rates. Continuous variables were described using mean and standard deviation (SD). T-test and one-way analyses of variance were used to compare hand hygiene reported in different levels of burnout, secondary traumatic stress and compassion satisfaction score. Simple linear regression was performed to determine the impact of burnout, secondary traumatic stress and compassion satisfaction on hand hygiene reported adjusted the socio-demographic characteristics. All statistical analyses were performed using IBM SPSS Version 20.0 (IBM, New York, NY, USA).

\section{Results}

A total of $1383(79.76 \%)$ nurses and 351(20.24\%) doctors were surveyed, including $1305(75.26 \%)$ female, $429(24.74 \%)$ male. The mean and SD of age and work year were $33.33 \pm 6.39$ and $10.90 \pm 6.48$, respectively. Most HCWs reported neutral (936[53.98\%]) and high (661[38.12\%]) workload. 
None of HCWs reported high burnout, with $69.61 \%$ in low level and $30.39 \%$ in average level. Most HCWs reported low (33.33\%) and average (66.21\%) level in secondary traumatic stress, and average (49.65\%) and high (49.71\%) level in compassion satisfaction. (Table 2)

Table 2

ProQOL' means, prevalence and SD

\begin{tabular}{|c|c|c|c|c|}
\hline ProQOL & Mean(min-max) & Prevalence (n [\%]) & & SD \\
\hline \multirow[t]{2}{*}{ Burnout } & \multirow[t]{2}{*}{$19.42(10.00-40.00)$} & $\operatorname{Low}(\leq 22)$ & $1207(69.61)$ & \multirow[t]{2}{*}{5.73} \\
\hline & & Average (23-41) & $527(30.39)$ & \\
\hline \multirow[t]{3}{*}{ Secondary traumatic stress } & \multirow[t]{3}{*}{$24.76(10.00-49.00)$} & $\operatorname{Low}(\leq 22)$ & 578(33.33) & \multirow[t]{3}{*}{5.09} \\
\hline & & Average $(23-41)$ & $1148(66.21)$ & \\
\hline & & High $(\geq 42)$ & $8(0.46)$ & \\
\hline \multirow[t]{3}{*}{ Compassion satisfaction } & \multirow[t]{3}{*}{$41.43(10.00-50.00)$} & $\operatorname{Low}(\leq 22)$ & $11(0.63)$ & \multirow[t]{3}{*}{6.49} \\
\hline & & Average (23-41) & $861(49.65)$ & \\
\hline & & High $(\geq 42)$ & $862(49.71)$ & \\
\hline
\end{tabular}

The overall hand hygiene reported was $4.82 \pm 0.31$. The lowest was the moment during work on a soiled body site to a clean body site on the same patient (4.34 \pm 0.93$)$, and the highest was the moment after removing PPE (4.95 \pm 0.26$)$. (Table 3) 
Table 3

Rank, Score mean and SD of self-reported hand hygiene

\begin{tabular}{|c|c|c|}
\hline Self-reported hand hygiene & Mean & SD \\
\hline Overall hand hygiene & 4.82 & 0.31 \\
\hline Low level of hand hygiene & 4.63 & 0.51 \\
\hline 1 during work on a soiled body site to a clean body site on the same patient & 4.34 & 0.93 \\
\hline 2 before toilet & 4.57 & 0.82 \\
\hline 3 before touching a patient & 4.61 & 0.70 \\
\hline 4 arriving at work place & 4.73 & 0.62 \\
\hline 5 after touching patient surroundings & 4.75 & 0.54 \\
\hline 6 before wearing glove & 4.78 & 0.57 \\
\hline Medium level of hand hygiene & 4.88 & 0.29 \\
\hline 7 before drinking & 4.85 & 0.43 \\
\hline 8 before putting on PPE & 4.86 & 0.43 \\
\hline 9 before aseptic procedure & 4.87 & 0.43 \\
\hline 10 after touching a patient & 4.88 & 0.39 \\
\hline 11 leaving work place & 4.88 & 0.39 \\
\hline 12 during removing PPE & 4.92 & 0.35 \\
\hline High level of hand hygiene & 4.94 & 0.24 \\
\hline 13 after removing glove & 4.93 & 0.32 \\
\hline 14 after toilet & 4.94 & 0.28 \\
\hline 15 after body fluid exposure risk & 4.94 & 0.30 \\
\hline 16 before returning to the place of residence & 4.94 & 0.27 \\
\hline 17 before removing PPE & 4.94 & 0.28 \\
\hline 18 after removing PPE & 4.95 & 0.26 \\
\hline
\end{tabular}

According to univariate analysis, HCWs with different secondary traumatic stress and compassion satisfaction reported different level of hand hygiene. The higher burnout in HCWs were associated with lower self-reported hand hygiene behavior in overall hand hygiene $(p<0.001)$, low level of hand hygiene $(p<0.001)$, medium level of hand hygiene $(p<0.001)$ and high level of hand hygiene $(p<0.001)$. (Table 4$)$ 
Table 4

Univariate analysis of hand hygiene reported and ProQOL

\begin{tabular}{|c|c|c|c|c|c|c|c|c|c|}
\hline & & \multicolumn{2}{|c|}{$\begin{array}{l}\text { Overall hand } \\
\text { hygiene }\end{array}$} & \multicolumn{2}{|c|}{$\begin{array}{l}\text { Low level of hand } \\
\text { hygiene }\end{array}$} & \multicolumn{2}{|c|}{$\begin{array}{l}\text { Medium level } \\
\text { of hand } \\
\text { hygiene }\end{array}$} & \multicolumn{2}{|c|}{$\begin{array}{l}\text { High level of hand } \\
\text { hygiene }\end{array}$} \\
\hline & & $\begin{array}{l}\text { Mean } \\
\text { (SD) }\end{array}$ & $p$ & $\begin{array}{l}\text { Mean } \\
\text { (SD) }\end{array}$ & $p$ & $\begin{array}{l}\text { Mean } \\
\text { (SD) }\end{array}$ & $p$ & $\begin{array}{l}\text { Mean } \\
\text { (SD) }\end{array}$ & $p$ \\
\hline \multirow[t]{2}{*}{ Burnout } & Low & $4.86(0.22)$ & \multirow{2}{*}{$<.001$} & $4.70(0.44)$ & \multirow{2}{*}{$<001$} & $4.92(0.19)$ & \multirow{2}{*}{$\begin{array}{l}<.001 \\
0.00\end{array}$} & $4.97(0.13)$ & \multirow{2}{*}{$<.001$} \\
\hline & Average & $4.70(0.42)$ & & $4.47(0.60)$ & & $4.77(0.42)$ & & $4.87(0.37)$ & \\
\hline \multirow{3}{*}{$\begin{array}{l}\text { Secondary } \\
\text { traumatic } \\
\text { stress }\end{array}$} & Low & $4.86(0.29)$ & \multirow{3}{*}{$<.001$} & $4.70(0.47)$ & \multirow{3}{*}{$<.001$} & $4.91(0.28)$ & \multirow{3}{*}{$\begin{array}{l}<.001 \\
0.001\end{array}$} & $4.96(0.24)$ & \multirow[t]{3}{*}{0.011} \\
\hline & Average & $4.79(0.31)$ & & $4.59(0.52)$ & & $4.86(0.30)$ & & $4.93(0.24)$ & \\
\hline & High & $4.96(0.07)$ & & $4.86(0.23)$ & & $5(0)$ & & $5(0)$ & \\
\hline \multirow{3}{*}{$\begin{array}{l}\text { Compassion } \\
\text { satisfaction }\end{array}$} & Low & $4.16(1.28)$ & \multirow{3}{*}{$<.001$} & $4.17(1.25)$ & \multirow{3}{*}{$<001$} & $4.14(1.27)$ & \multirow{3}{*}{$\begin{array}{l}< \\
0.001\end{array}$} & $4.21(1.27)$ & \multirow{3}{*}{$\begin{array}{l}< \\
0.001\end{array}$} \\
\hline & Average & $4.74(0.34)$ & & $4.51(0.55)$ & & $4.82(0.33)$ & & $4.91(0.27)$ & \\
\hline & High & $4.89(0.19)$ & & $4.76(0.40)$ & & $4.95(0.16)$ & & $4.98(0.10)$ & \\
\hline
\end{tabular}

According to the multivariate analysis, burnout was negatively associated with overall hand hygiene (Coef. $=-0.088, p<$ 0.001 ), low level of hand hygiene (Coef. $=-0.109, p<0.001$ ), medium level of hand hygiene (Coef. $=-0.088, p<0.001$ ) and high level of hand hygiene (Coef. $=-0.065, p<0.001$ ). It was also found that the effect of burnout was larger as the absolute value of coefficient increased, with decreasing score of hand hygiene reported. HCWs with higher compassion satisfaction reported higher hand hygiene behavior, and the coefficient increased with higher-score hand hygiene. In addition, HCWs with older age were negatively associated with self-reported hand hygiene in the overall hand hygiene (Coef. $=-0.005, p=0.079$ ) and low level (Coef. $=-0.010, p=0.052$ ). Nurses reported higher hand hygiene in low level (Coef. $=0.117, p=0.005)$ compared to doctors. Female HCWs reported higher hand hygiene in high score (Coef. $=0.039$, $p=0.013$ ) compared to male. (Table 5) 
Table 5

Multivariable regression analysis of ProQOL with hand hygiene reported

\begin{tabular}{|c|c|c|c|c|}
\hline Hand hygiene reported & & Coef. & Std. Err. & $\mathbf{p}$ \\
\hline \multicolumn{5}{|l|}{ Overall hand hygiene } \\
\hline Burnout & & -0.088 & 0.019 & $<0.001$ \\
\hline \multirow[t]{3}{*}{ Compassion Satisfaction } & Ref & & & \\
\hline & 2 & 0.556 & 0.089 & $<0.001$ \\
\hline & 3 & 0.661 & 0.090 & $<0.001$ \\
\hline Age & & -0.005 & 0.003 & 0.079 \\
\hline \multicolumn{5}{|l|}{ Low hand hygiene } \\
\hline Burnout & & -0.109 & 0.032 & 0.001 \\
\hline \multirow[t]{3}{*}{ Compassion Satisfaction } & Ref & & & \\
\hline & 2 & 0.337 & 0.149 & 0.024 \\
\hline & 3 & 0.532 & 0.151 & $<0.001$ \\
\hline Career & & 0.117 & 0.041 & 0.005 \\
\hline Age & & -0.010 & 0.005 & 0.052 \\
\hline \multicolumn{5}{|l|}{ Medium hand hygiene } \\
\hline Burnout & & -0.088 & 0.018 & $<0.001$ \\
\hline \multirow[t]{3}{*}{ Compassion Satisfaction } & Ref & & & \\
\hline & 2 & 0.658 & 0.085 & $<0.001$ \\
\hline & 3 & 0.738 & 0.086 & $<0.001$ \\
\hline \multicolumn{5}{|l|}{ High hand hygiene } \\
\hline Burnout & & -0.065 & 0.015 & $<0.001$ \\
\hline \multirow[t]{3}{*}{ Compassion Satisfaction } & Ref & & & \\
\hline & 2 & 0.673 & 0.070 & $<0.001$ \\
\hline & 3 & 0.713 & 0.071 & $<0.001$ \\
\hline Gender & & 0.039 & 0.016 & 0.013 \\
\hline
\end{tabular}

\section{Discussion}

This study assessed the prevalence of burnout, secondary traumatic stress and compassion satisfaction based on ProQOL scale and explored their impact on self-reported hand hygiene behavior among medical aid team during COVID19 pandemic. Most HCWs experience low and average level of burnout and secondary traumatic stress, and average and high level of compassion satisfaction. HCWs with lower burnout and higher compassion satisfaction reported higher level of hand hygiene. 
The overall reported hand hygiene was consistent with previous self-reported hand hygiene during MERS-CoV outbreak[20,21]. Interestingly, we can find that the level of burnout is lower and secondary traumatic stress is higher than previous researches conducted in China and other countries, during the period without the emerging infectious diseases[14, 16, 17, 22]. In general, HCWs reported more psychological burden, when they were exposed to the center of outbreak, had experience in caring for infected or suspected patient and in the frontline[23, 24]. The opposite result we obtained may be associated with the greater effect of promotion activities acting on the HCWs compared to the pandemic, which includes careful management from hospital, the positive report and higher social status in HCWs from the public during the pandemic. The experience of zero infection in medical aid team also proves the effective management in medical aid team, in the aspect of protective equipment. In addition, we can observe that the environment of management and public may be highly associated with the burnout and compassion satisfaction of HCWs[25, 26].

As for the impact to hand hygiene behavior, we find that burnout, compassion satisfaction, age, career and gender are the influencing factors of hand hygiene behavior. More precisely, lower burnout, higher compassion satisfaction, nurse (vs. doctor), younger age and male (vs. female) promoted hand hygiene behavior, which is consistent with previous studies that high burnout in HCWs frequently is associated with poor-quality care, including adherence to management guidelines, medical error, healthcare-associated infections[12]. Colindres and Manomenidis also found that burnout was an incremental predictor of adherence to the measures of infection control including hand hygiene[7, 8]. And Dasan found that consultants with lower compassion satisfaction were more irritable with patients or colleagues and reducing their standards of care[14]. We also find that the effect of burnout and compassion satisfaction are larger in the hand hygiene of low score compared to the high, which means the improvement of burnout and compassion satisfaction can advance hand hygiene behavior of low score more effectively. That also emphasizes the importance of burnout and compassion satisfaction in hand hygiene behavior. Thus, burnout and compassion satisfaction in HCWs, especially in medical aid team, should be paid more attention [8].

Just like previous studies, nurses career, female and younger age can be associated with higher score of hand hygiene[3], probably because of the differences in the presence and level of training between careers[27], inter gender differences from parents[28], etc..

Relevant intervention is the approach to reduce burnout and increase compassion satisfaction. The individual-based interventions include mindfulness-based technique, educational, emotions empowerment[29, 30]. The organizationdirected interventions include increased support for clinical work, structural changes, routine staff meetings, improving the work environment, etc.[20,31]. To improve hand hygiene behavior and compassion satisfaction and relieve burnout in pandemic, the managers should take more into consideration and intervention targeting should be performed. Based on the relatively lower burnout and compassion satisfaction we obtained, the management of HCWs in Wuhan, China may be constructive for future medical aid team.

This work reveals implications and experience for emergent preparedness and HCW resource management. Firstly, the experience of management of HCWs in medical aid team in China has referential meaning to combat COVID-19, for the zero infection, lower burnout and higher compassion satisfaction in these population. Secondly, as lower burnout and higher compassion satisfaction are associated with better hand hygiene behavior, the improvement of burnout and compassion should be emphasized, which can be obtained by intervention. Thirdly, the public and managers should respect HCWs and emphasize their importance, so as too in general period, which may be highly associated with the burnout in HCWs. This study has limitations that we didn't assess the effect of intervention of management of medical aid team, because of the baseline data was unavailable. 


\section{Conclusions}

Most HCWs in medical aid team experience lower level burnout, and higher level of compassion satisfaction during COVID-19 pandemic compared to the general period. The lower burnout, higher compassion satisfaction, nurse (vs. doctor), younger age and male (vs. female) are associated with higher self-reported hand hygiene behavior. And the lower hand hygiene behavior is, the greater effect of burnout and compassion satisfaction are. Burnout and compassion satisfaction in HCWs should be emphasize and need interventions targeting the management of burnout and compassion satisfaction. The management of HCWs in Wuhan, China may be constructive for future medical aid team.

\section{Abbreviations}

HCWs: healthcare workers; ProQOL: Professional quality of life; PPE: personal protective equipment; SD: standard deviation; IPC: infection prevention and control

\section{Declarations}

\section{Ethics approval and consent to participate}

The study was approved by Ethics Committee of Tongji Medical College, Huazhong University of Science and Technology. All participants were enrolled in the investigation using the principles of informed consent and confidentiality.

\section{Consent for publications}

Not applicable.

\section{Availability of data and materials}

The datasets used and/or analyzed during the current study are available from the corresponding author on reasonable request.

\section{Competing interests}

The authors declare that they have no competing interests.

\section{Funding}

This study was supported by the National Natural Science Foundation of China [grant numbers.71974062].

\section{Authors' contributions}

QZ Conceptualized, analyzed, interpreted data and drafted the manuscript. XPZ conceptualized and drafted manuscript. LT and XQL were responsible for data collection. CYW helped the process of drafting.

\section{Acknowledgements}

We thank the cooperation of healthcare workers in medical aid teams coming for Hubei province from across the country in data collection and their devotions for people. We also thank the hard work from healthcare worker of Tongji hospital in data collection. 


\section{References}

1. Zhang M. Protecting healthcare workers in China during the coronavirus outbreak. BMJ. 2020.

2. Shah K, Chaudhari G, Kamrai D, Lail A, Patel RS. How Essential Is to Focus on Physician's Health and Burnout in Coronavirus (COVID19. Pandemic? CUREUS. 2020;12(4):e7538;. doi:10.7759/cureus.7538.

3. Erasmus V, Daha TJ, Brug H, Richardus JH, Behrendt MD, Vos MC, et al. Systematic Review of Studies on Compliance with Hand Hygiene Guidelines in Hospital Care. Infect Control Hosp Epidemiol. 2010;31(3):283 - 94;. doi:10.1086/650451.

4. Raab M, Pfadenhauer LM, Millimouno TJ, Hoelscher M, Froeschl G. Knowledge, attitudes and practices towards viral haemorrhagic fevers amongst healthcare workers in urban and rural public healthcare facilities in the N'zerekore prefecture, Guinea: a cross-sectional study. BMC Public Health. 2020;20(1):296;doi. 10.1186/s12889020-8433-2.

5. Dauda Goni M, Hasan H, Naing NN, Wan-Arfah N, Zeiny Deris Z, Nor Arifin W, et al. Assessment of Knowledge, Attitude and Practice towards Prevention of Respiratory Tract Infections among Hajj and Umrah Pilgrims from Malaysia in 2018. Int J Environ Res Public Health. 2019;16(22):4569;doi. 10.3390/ijerph16224569.

6. Akinyinka MR, Bakare OQ, Oluwole EO, Odugbemi BA. Hand hygiene practices in the context of Ebola virus disease: A cross-sectional survey of Lagos residents. J Infect Prev. 2019;20(4):179 - 84;. doi:10.1177/1757177419830779.

7. Colindres CV, Bryce E, Coral-Rosero P, Ramos-Soto RM, Bonilla F, Yassi A. Effect of effort-reward imbalance and burnout on infection control among Ecuadorian nurses. Int Nurs Rev. 2018;65(2):190-9. doi:10.1111/inr.12409.

8. Manomenidis G, Panagopoulou E, Montgomery A. Job Burnout Reduces Hand Hygiene Compliance Among Nursing Staff. J Patient Saf. 2019;15(4):e70-e3. doi:10.1097/PTS.0000000000000435.

9. Sim K, Chua HC. The psychological impact of SARS:a matter of heart and mind. CMAJ. 2004;170(5):811-2.

10. Li Y, Wang H, Jin XR, Li X, Pender M, Song CP, et al. Experiences and challenges in the health protection of medical teams in the Chinese Ebola treatment center, Liberia a qualitative study. Infect Dis Poverty. 2018;7(1):92;doi. 10.1186/s40249-018-0468-6.

11. Stamm BH. The Concise ProQOL Manual. 2nd ed2010.

12. Tawfik DS, Scheid A, Profit J, Shanafelt T, Trockel M, Adair KC, et al. Evidence Relating Health Care Provider Burnout and Quality of Care: A Systematic Review and Meta-analysis. Ann Intern Med. 2019. doi:10.7326/M191152.

13. Harolds JA. Quality and Safety in Health Care, Part XLV Introduction to Burnout. Clin Nucl Med. 2019;44(3):221-2. doi:10.1097/RLU.0000000000002437.

14. Dasan S, Gohil P, Cornelius V, Taylor C. Prevalence, causes and consequences of compassion satisfaction and compassion fatigue in emergency care: a mixed-methods study of UK NHS Consultants. Emerg Med J. 2015;32(8):588 - 94;. doi:10.1136/emermed-2014-203671.

15. $10.1136 / \mathrm{bmj} . \mathrm{I}$

Rico-Campà A, Martínez-González MA, Alvarez-Alvarez I, Mendonça RD, de la Fuente-Arrillaga C, Gómez-Donoso C, et al. Association between consumption of ultra-processed foods and all cause mortality: SUN prospective cohort study. BMJ. 2019;365:I1949;doi:10.1136/bmj.I1949.

16. Shen J, Yu H, Zhang Y, Jiang A. Professional quality of life:A cross-sectional survey among Chinese clinical nurses. Nurs Health Sci. 2015;17(4):507 - 15;. doi:10.1111/nhs.12228.

17. Wang J, Okoli CTC, He H, Feng F, Li J, Zhuang L, et al. Factors associated with compassion satisfaction, burnout, and secondary traumatic stress among Chinese nurses in tertiary hospitals: A cross-sectional study. Int J Nurs Stud. 2020;102:103472;. doi:10.1016/j.ijnurstu.2019.103472. 
18. Christian-Brandt AS, Santacrose DE, Barnett ML. In the trauma-informed care trenches: Teacher compassion satisfaction, secondary traumatic stress, burnout, and intent to leave education within underserved elementary schools. Child Abuse Negl 2020:104437;doi:10.1016/j.chiabu.2020.104437.

19. Polat $H$, Turan GB, Tan M. Determination of the relationship of the spiritual orientation of nurses with compassion fatigue, burnout, and compassion satisfaction. Perspect Psychiatr Care. 2020. doi:10.1111/ppc.12513.

20. Yang J, Park EC, Lee SA, Lee SG. Associations Between Hand Hygiene Education and Self-Reported Hand- Washing Behaviors Among Korean Adults During MERS-CoV Outbreak. Health Educ Behav. 2019;46(1):157 - 64;. doi:10.1177/1090198118783829.

21. Alshammari M, Reynolds KA, Verhougstraete M, O'Rourke MK. Comparison of Perceived and Observed Hand Hygiene Compliance in Healthcare Workers in MERS-CoV Endemic Regions Healthcare (Basel). 2018;6(4);doi:10.3390/healthcare6040122.

22. Woo T, Ho R, Tang A, Tam W. Global prevalence of burnout symptoms among nurses: A systematic review and meta-analysis. JOURNAL OF PSYCHIATRIC RESEARCH. 2020;123:9-20;. doi:10.1016/j.jpsychires.2019.12.015.

23. Lai J, Ma S, Wang Y, Cai Z, Hu J, Wei N, et al. Factors Associated With Mental Health Outcomes Among Health Care Workers Exposed to Coronavirus Disease 2019. JAMA Netw Open. 2020;3(3):e203976.

doi:10.1001/jamanetworkopen.2020.3976.

24. Kim JS, Choi JS. Factors Influencing Emergency Nurses' Burnout During an Outbreak of Middle East Respiratory Syndrome Coronavirus in Korea. Asian Nurs Res (Korean Soc Nurs Sci). 2016;10(4):295-9;.

doi:10.1016/j.anr.2016.10.002.

25. Chung SY, Dillon EC, Meehan AE, Nordgren R, Frosch DL. The Relationship Between Primary Care Physician Burnout and Patient-Reported Care Experiences: a Cross-sectional Study. JOURNAL OF GENERAL INTERNAL MEDICINE. 2020;doi:10.1007/s11606-020-05770-w.

26. Saeidi R, Izanloo A, Izanlou S. A Study of the Relationship between Job Satisfaction and Burnout among Neonatal Intensive Care Unit Staff. IRANIAN JOURNAL OF NEONATOLOGY. 2020;11(1):67-70; doi:10.22038/ijn.2019.39744.1634.

27. Rose L, Rogel K, Redl L, Cade JF. Implementation of a multimodal infection control program during an Acinetobacter outbreak. Intensive Crit Care Nurs. 2009;25(2):57-63;. doi:10.1016/j.iccn.2008.09.002.

28. van de Mortel T, Bourke R, McLoughlin J, Nonu M, Reis M. Gender influences handwashing rates in the critical care unit. Am J Infect Control. 2001;29(6):395-9.

29. West CP, Dyrbye LN, Shanafelt TD. Physician burnout: contributors, consequences and solutions. J Intern Med. 2018;283(6):516 - 29;. doi:10.1111/joim.12752.

30. Janssen M, Heerkens Y, Kuijer W, van der Heijden B, Engels J. Effects of Mindfulness-Based Stress Reduction on employees' mental health: A systematic review. PLoS One. 2018;13(1):e0191332.

doi:10.1371/journal.pone.0191332.

31. Bresesti I, Folgori L, De Bartolo P. Interventions to reduce occupational stress and burn out within neonatal intensive care units: a systematic review. Occup Environ Med. 2020:oemed-2019-106256;doi:10.1136/oemed-2019106256. 